\title{
Concurrent Onset of Pulmonary and Articular Symptoms - Rare Manifestation of Rheumatoid Arthritis Associated Interstitial Lung Disease: A Case Report
}

\author{
RAHIM MA ${ }^{\mathrm{a}}$, PARVIN $\mathrm{S}^{\mathrm{b}}$, ZAMAN $\mathrm{S}^{\mathrm{c}}$, HAQUE HF ${ }^{\mathrm{a}}$ RAHMAN MM ${ }^{\mathrm{d}}$, AFROZ SR ${ }^{\mathrm{a}}$, AFROZE Fa ${ }^{\mathrm{a}}$, AHMED JU' \\ AHMED AKMS ${ }^{\mathrm{a}}$, HOSSAIN MD ${ }^{\mathrm{a}}$, RAHMAN MR ${ }^{\mathrm{a}}$, MUSAAKM ${ }^{\mathrm{a}}$, UDDIN KN ${ }^{\mathrm{a}}$
}

\begin{abstract}
Lung is the most common extra-articular site of involvement in rheumatoid arthritis (RA). It can involve pleura, lung parenchyma and pulmonary vasculature. Among many diseases, most debilitating one is $R A$ associated interstitial lung disease (RA-ILD). Here, we describe a middle aged Bangladeshi lady who presented because of progressively
\end{abstract}

\section{Introduction}

Rheumatoid lung is a common condition, occurring in upto $54 \%$ of rheumatoid arthritis (RA) cases. ${ }^{1,2}$ Pulmonary diseases in RA is the second leading cause of death. ${ }^{3}$ Among the various patters of pulmonary diseases, interstitial lung disease (ILD) represents the most severe one, accounting for $20-30 \%$ cases. ${ }^{4}$ Risk factors for RA associated ILD (RA-ILD) includes male sex, smoking, high titres of rheumatoid factor (RF) and anti-CCP antibody, environmental exposures, methotrexate and other disease modifying anti-rheumatic drugs etc. ${ }^{5,6}$

Usually RA-ILD is suspected when long standing RA patients present with non-productive cough and

a. Dr. Muhammad Abdur Rahim, FCPS (Medicine), Dr. Hasna Fahmima Haque, FCPS (Medicine), Registrar, Dr. Samira Rahat Afroz, FCPS (Medicie), MO, Dr. Farhana Afroz, FCPS (Medicine), SMO, Dr. Jamal Uddin Ahmed, FCPS (Medicine), Asst. Prof, Dr. AKM Shaheen Ahmed, FCPS (Medicine), Dr. Md. Delwar Hossain, MD (Chest), Dr. Md. Raziur Rahman, MD (Medicine), Asso. Professor, Prof. AKM Musa, FCPS (Medicine) and Prof. Khwaja Nazim Uddin, FCPS (Medicine), Head, Department of Internal Medicine, BIRDEM.

b. Dr. Shahana Parveen, DEM, SMO, Department of Cardiology, BIRDEM.

c. Dr. Shahana Zaman, FCPS (Cardiology), Registrar, Department of Cardiology, NICVD.

d. Dr. Md. Mahbubur Rahman, MD (Gastro), SMO, Department of GHPD, BIRDEM.

Address of correspondence: Dr. Muhammad Abdur Rahim, FCPS (Medicine), Registrar, Department of Internal Medicine and Rheumatology, Ibrahim Medical College and BIRDEM General Hospital, Shahbag, Dhaka. Email: muradrahim23 @yahoo.com.

Received: April 28, 2012

Accepted: December 31, 2013 deteriorating non-productive cough, exertional dyspnea and polyarthritis of 5 month duration. Diagnostic workup confirmed RA-ILD and she responded well with prednisolone, hydroxychloroquine and azathioprine.

Key words: articular, concurrent, interstitial lung disease, pulmonary, rheumatoid arthritis.

(Birdem Med J 2014; 4(1): 47-49)

exertional dyspnea. Rarely patients may present with corpulmonale. ${ }^{7}$ In some cases, RA manifest later in established ILD cases. ${ }^{8,9}$ But simultaneous onset of pulmonary and articular symptoms are rare. ${ }^{5}$ Here, we present such a case.

\section{Case Report}

A 65-year-old diabetic lady presented with 5 month history of progressively deteriorating non-productive cough, exersional dyspnoea and polyarthritis involving all small and large joints including hand joints with significant morning stiffness. She did not have any chest pain, palpitation or rash. She lost $3 \mathrm{~kg}$ in weight during this period.

The lady was moderately anaemic. There was no rash or lymphadenopathy. She had bilateral crepitation upto the midchest. Her metacarpophalangeal and proximal interphalangeal joints were swollen and tender and there was swan neck deformity in $3^{\text {rd }}$ and $4^{\text {th }}$ fingers bilaterally. Her limb movements were restricted because of pain. There was no intra-abdominal organomegaly. Other examination findings were unremarkable.

Her haemoglobin was $10.4 \mathrm{gm} / \mathrm{dl}$, normochromic normocytic, total and differential white cell count was normal, platelet count was 4,79,000/cmm, ESR- 100 mm in 1st hour, CRP- 24 mg/dl. Her fasting blood glucose was $11.8 \mathrm{mmol} / \mathrm{L}$, HbA1c- $8.9 \%$.

Chest $\mathrm{X}$-ray PA view revealed increased reticular shadowing in both bases and periphery suggesting 
interstitial lung disease (Figure 1). X-ray hand was normal. Arterial blood gas analysis showed mild alkalosis. Pulmonary function test revealed mild restricrive disease.

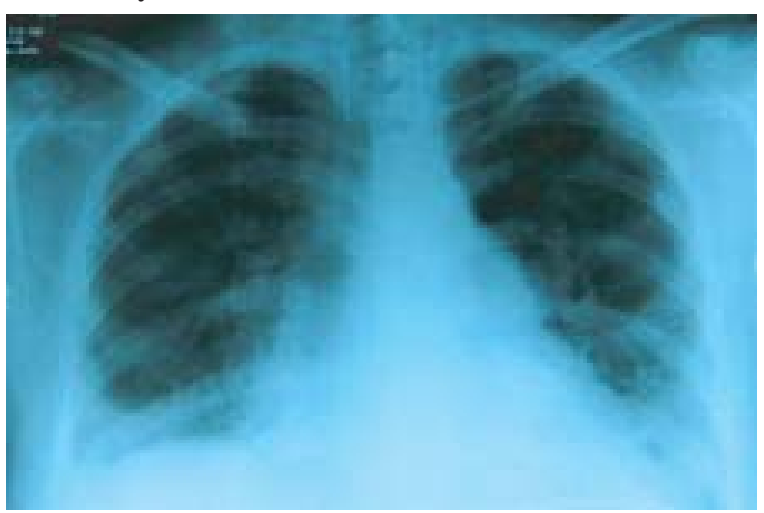

Fig.-1: Chest $x$-ray PA view showing increased reticular shadowing in both bases and periphery

Routine biochemical tests including renal function, liver function, serum electrolytes including calcium were normal. Tuberculin test showed $7 \mathrm{~mm}$ induration at 72 hours. ECG was normal and echocardiography did not reveal pulmonary hypertension.

High resolution CT (HRCT) scan of chest revealed diffuse infiltration, reticulation, ground glass opacity and sub-pleural honeycombing with peripheral and posterior predominance in both lung fields consistent with interstitial lung disease (Figure 2). Rheumatoid factor (RF) was > $128 \mathrm{IU} / \mathrm{mL}$, anti-CCP antibody was positive; ANA and anti-RNP were negative.

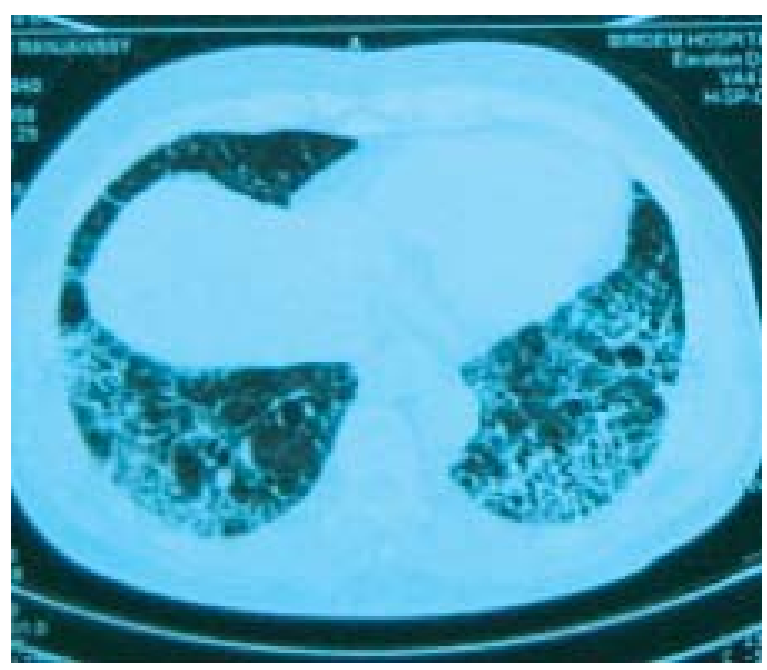

Fig.-2: HRCT scan of chest showing diffuse infiltration, reticulation, ground glass opacity and sub pleural honeycombing with peripheral and posterior predominance bilaterally
So, the patient was finally diagnosed as a case of RAILD and diabetes mellitus (DM). Treatment was started with ibuprofen, prednisolone, hydroxychloroquine and azathioprine. For DM she was receiving premixed insulin and metformin.

\section{Discussion}

Pulmonary fibrosis and pleural effusion are two most common pulmonary manifestation of RA. ${ }^{10}$ Pathologically, five different groups of disorders are identified; rheumatoid pulmonary nodule, usual interstitial pneumonia (UIP), non-specific interstitial pneumonia (NSIP), bronchiolitis obliterance with organizing pneumonia (BOOP), lymphoid hyperplasia and cellular interstitial infiltrates. Usually pulmonary fibrosis results from a slowly progressive interstitial disease (UIP/NSIP). Open lung biopsy, which carries a significant morbidity, can give a definitive diagnosis, but the advent of HRCT scan has largely replaced it now a days. In our case, ILD was diagnosed by HRCT of chest and lung biopsy was not done.

Typically RA-ILD develops in male patients in $4^{\text {th }}$ to $5^{\text {th }}$ decades. ${ }^{6}$ Smoker with high RF and anti-CCP antibody titres are more vulnerable, implies that there might be some pulmonary reaction to autoantibodies produced in RA. ${ }^{5}$ Conversely, in cases of ILD without RA, presence of autoantibodies specific for RA may imply that environmental factors exposed to lung may initiate the immunological reaction that may ultimately target synovial joints to produce RA. ${ }^{8}$ It is obvious that, concurrent onset of pulmonary and articular symptoms mandate careful exclusion of sarcoidosis, vasculitis, adverse drug reactions and other differentials. Our patient was a female in her 50s, non-smoker with high titres of RF and anti-CCP antibody and we also excluded the differentials.

Lung function tests in ILD typically show restrictive pattern with reduced carbon-monoxide transfer factor. ${ }^{6}$ In our case, spirometry revealed moderate restrictive disease.

Treatment includes proper control of RA and ILD with corticosteroids and immune suppressive agents. The initial response in our case with prednisolone, hydroxychloroquine and azathioprine looked good. Overall prognosis is disappointing, median survival after diagnosis is 2.6 years. ${ }^{11}$ However, aggressive immune suppression with rituximab, heart lung transplantation 
and other experimental agents may improve the overall outcome in future. ${ }^{6}$

\section{Conclusion}

Though uncommon, it is not impossible to present simultaneous onset of respiratory and joint symptoms in RA-ILD. High index of suspicion and careful exclusion of other differentials are necessary.

\section{References}

1. Fujii M, Adachi S, Shimizu T, Hiroto T, Sako M, Kono M. Interstitial lung disease in rheumatoid arthritis: assessment with high-resolution computed tomography. J Thoracic Imaging 1993; 8(1):54-62.

2. Gabbay E, TaralaR, Will R. Interstitial lung disease in recent onset rheumatoid arthritis. American J Resp Crit Care Med 1997; 156(2):528-35.

3. Toyoshima H, Kusaba T, Yamaguchi M. Cause of death in autopsied RA patients. Ryumachi 1993; 33(3):209-14.

4. McDonagh J, Greaves M, Wright AR, Heycock C, Owen JP, Kelly C. High resolution computed tomography of the lungs in patients with rheumatoid arthritis and interstitial lung disease. British J Rheumatol 1994; 33(2):118-22.

5. Mori S, Cho I, Koga Y, Sugimoto M. A simultaneous onset of organizing pneumonia and rheumatoid arthritis, along with a review of the literature. Mod Rheumatol 2008;18(1):60-66.

6. Hamblin MJ, Horton MR. Rheumatoid Arthritis Associated Interstitial Lung Disease: Diagnostic Dilemma. Pulmonary Medicine 2011;Article ID 872120 (cited jan. 6, 2012).

7. Acharya S, Mahajan SN, Shukla S, Diwan SK, Banode P, Kothari N. Rheumatoid interstitial lung disease presenting as corpulmonale. Lung India 2010; 27(4): 256-59.

8. Gizinski GM, Mascolo M, Loucks JL, Kervitsky A, Meehan RT, Brown KK, et al. Rheumatoid arthritis (RA) specific autoantibodies in patients with interstitial lung disease and absence of clinically apparent articular RA. Clin Rheumatol 2009;28:611-13.

9. Tomiokaa H, Kanekoa M, Kogatab Y, Katsuyamac E, Ishikawad S, Fujiid T. A case of interstitial lung disease with anti-EJ and anti-CCP antibodies preceding rheumatoid arthritis. Respiratory Investigation 2012; 50(2): 66-69.

10. Anaya JM, Diethelm L, Ortiz LA, Gutierrez M, Citera G, Welsh RA, et al. Pulmonary involvement in rheumatoid arthritis. Semin Arthritis Rheum 1995; 24: 242-54.

11. Bongartz T, Nannini C, Medina-Velasquez YF, Achenbach SJ, Crowson CS, Ryu JH, et al. Incidence and mortality of interstitial lung disease in rheumatoid arthritis: a population-based study. Arthritis Rheum 2010; 62(6): 1583-91. 